\title{
Project E-Lingap: Support in improving mastery level in health education 4
}

Capuz, Juliet $\bowtie$

Emilio Aguinaldo College, Philippines (julietcapuz.mnl@eac.edu.ph)

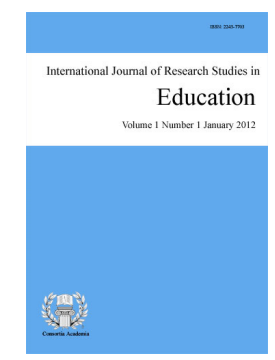

Accepted: 10 June 2021 Online ISSN: 2243-7711

OPEN ACCESS

\section{Abstract}

The purpose of this action research was to enhance learning through intensified nutrition and hygiene goals and awareness in improving academic performance in the Health of Grade Four pupils in Buenavista-Cigaras Elementary School. The study used the Mastery Level of Achievement Indicators in determining the academic performance in Health of Grade Four pupils. The collected data obtained were tabulated in tables and interpreted using the Mean Percentage Score and Score Analysis. The result of the study showed the enhanced learning through intensified nutrition and hygiene goals and awareness in improving mastery level of achievement. The research was limited to 8 Grade 4 pupils in Buenavista-Cigaras Elementary School who have been reported as SBFP clientele and belong to severely wasted \& wasted pupils. This research was designed for 8 months. There are very few simple solutions to human and economic development. But one is readily available to virtually everyone. Proper handwashing with soap and water is the world's most cost-efficient and effective preventative health measure. Yet, only a fraction of our global population fully employs this life-saving practice. Latrines, clean water, and immunizations are necessary health initiatives. However, washing hands with soap save more lives than any single vaccine or other medical intervention. This study tries to enhance learning through intensified nutrition and hygiene goals and awareness in improving academic performance in the Health of Grade Four pupils in Buenavista-Cigaras Elementary School.

Keywords: personal hygiene, nutrition, mastery level of achievement, health, academic performance 


\section{Project E-Lingap: Support in improving mastery level in health education 4}

\section{Introduction}

Numerous factors are known to affect the academic performance of students. These include prenatal conditions, birth conditions, postnatal events, nutritional, socio-economic factors, and environmental factors. Personal hygiene helps keep your immune system from being overwhelmed by the on-slot of germs. Skin is an important part of the immune system for it acts as a barrier between germs and your body. Skin is tough and generally impermeable to bacteria and viruses. On the other hand, germs can enter our bodies through other areas that are susceptible to bacteria such as our nose, mouth, eyes, or a break in the skin. Common sense and following good personal hygiene will limit the possibility of these germs finding a way into your body. Eating healthy balanced meals is especially important to a person who is recovering from an illness.

\subsection{Personal hygiene}

According to Lindsay Dingwall (2010) that meeting the hygiene needs of patients is a fundamental aspect of nursing care. This practical and introductory guide outlines and emphasizes the nursing skills required to meet the essential personal hygiene care needs of patients in various healthcare settings. It explores care of the eyes, ears, mouth, nails, and hair, and provides evidence-based rationales for each procedure. Methods of washing the patient are discussed, and bed-making and patient positioning is explored. Each chapter provides the necessary anatomy and physiology, as well as common conditions, safety issues, privacy and dignity, cultural and religious considerations, and infection control issues. Special Feature identifies the theoretical base underpinning clinical procedures Provides a research and evidence base for nursing practice Equips registered and non-registered staff with the knowledge to car

Good hygiene is an important barrier to many infectious diseases, including fecal-oral diseases, and it promotes better health and well-being. To achieve the greatest health benefits, improvements in hygiene should be made concurrently with improvements in the water supply and sanitation, and be integrated with other interventions, such as improving nutrition and increasing incomes. The next sections discuss how to improve personal and community hygiene practices that help to prevent the spread of fecal-oral diseases. If wastewater is not disposed of effectively it can serve as a breeding ground for mosquitoes. People may also slip and fall in muddy puddles, and children may play in them and risk waterborne illness. Personal and domestic hygiene and handwashing. Proper handwashing is one of the most effective ways of preventing the spread of diarrheal diseases. Pathogens cannot be seen on hands, and water alone is not always sufficient to remove them. Soap and wood ash are both cleansing and disinfecting agents when used with water and can be used to kill pathogens on hands and utensils. The most important times that hands should be washed with soap and water are $\bullet$ After defecating. • After cleaning a child who has defecated. • Before eating or handling food.

Leibler et al. (2017) stated that persons experiencing homelessness in the United States experience significant barriers to self-care and personal hygiene, including limited access to clean showers, laundry, and handwashing facilities. While the obstacles to personal hygiene associated with homelessness may increase the risk of infectious disease, hygiene-related behaviors among people experiencing homelessness have received limited attention. We conducted a cross-sectional study of individuals experiencing homelessness in Boston, MA $(n=194)$ to identify hygiene-related self-care practices and risk factors for reduced hygiene in this population. Most participants (72\%) reported taking a daily shower. More than $60 \%$ reported handwashing with soap five or more times each day, and the use of hand sanitizer was widespread (89\% reported using sanitizer in the last week). A majority (86\%) used a laundromat or laundry machine to wash clothing, while $14 \%$ reported washing clothing in the sink. Heavy drinking, injection drug use, and sleeping outdoors were identified as significant risk factors for reduced hygiene practices. People experiencing homelessness who also engage in these activities may be among the most difficult to reach for 
intervention, yet targeted efforts may decrease illness risk associated with reduced hygiene. Housed friends and family play a critical role in assisting homeless individuals to maintain hygiene by providing showers and laundry facilities.

It is thought that good hygiene habits, such as avoiding the use of other people's items may help in the reduction of communicable diseases. Handwashing compliance is a recognized tool in terms of quality and care in various countries around the world. Still, the infection rate is high in many parts of the world, even though hygiene education and health resources are available, so the problem arises from personal practice and behavior in the community. Hand hygiene also plays a role in minimizing acute respiratory infections. The majority of influenza-like illness (ILI) is caused by many different agents that are not clinically distinguishable from one another. A variable proportion of ILI ( 7 to $15 \%$ on average) is caused by influenza viruses and is known as influenza. Seasonal influenza has been estimated to cause 90 million new acute respiratory infection cases worldwide among young children in 2008, and 19,244 disability-adjusted life years lost across all age groups.

Vaccination against influenza is the primary way to reduce the substantial health burden that seasonal influenza causes, and is the primary tool to prevent influenza infection. A study during the H1N1 epidemic assessed the knowledge and attitudes of the Saudi public reported that $38.3 \%$ of participants were not convinced about the truth of published reports about this illness. Of those participants, $16.1 \%$ reported receiving information from health providers about influenza-related guidelines. Another study during the same epidemic confirmed the need for prevention strategies, including immunization and improved personal hygiene in the Saudi population.

In the study conducted by Abdulrahman et al. (2019) that the hygiene habits of young people may be motivated by perceptions of socially acceptable behavior rather than by scientific knowledge. Disease intervention studies suggest that the risk of infectious intestinal disease can be reduced by up to $31 \%$ through hand hygiene. Several studies have reported an association between improvements in hand hygiene and reductions in rates of intestinal parasitic diseases. However, only some have addressed the link between personal hygiene, influenza vaccine, and the frequency of influenza-like illness. The current study aims to find the association between personal hygiene habits and the frequency of influenza-like illness.

\subsection{Nutrition}

The typical Filipino diet mainly consists of rice, fish, and vegetables, with rice being the greatest source of calories. The consumption of maize, starchy roots, and tubers as rice substitutes or supplements, and vegetables and fruits has generally declined, while the consumption of fats, oils, and meats has increased. Stunting is the most prevalent form of malnutrition among Filipinos. Vitamin A Deficiency, Iodine Deficiency Disorder, and Iron Deficiency Anemia remain public health problems for children and pregnant and lactating women. The link between nutrition and agriculture in the Philippines has focused on leveraging agriculture to improve nutrition. The programs that had been initiated by the government, NGO/CSO, or private sector were conceptualized and implemented before the elements of a nutrition-sensitive agriculture framework were identified. These programs were implemented to address food production and the nutritional needs of individuals, families, and communities only about nutrition security. Many of these programs have been successful as they implemented best practices that could be applied to forge a superior approach that optimizes the agriculture-nutrition nexus.

This study identified these best practices or elements of success. The elements that have been noted as reasons for the success of some of these programs are: the presence of strong political will and enabling policy environment; forging of new forms of partnerships, strategic collaboration, sound coordination, and structures; exploiting the best that science and technology could offer; democratizing community participation; strong capacity-building component and access to reliable technical expertise; knowledge and sensitivity to local cultures, beliefs, and practices; professionalized promotion and 'messaging'; use of catchy terms for easy recall; availability of sustainable funding; use of the life cycle approach in nutrition; holistic community nutrition perspective; practice and promotion of biodiversity-based agricultural production system; and control of the 
means of production.

According to Jeukendrup (2017) that it is becoming increasingly clear that adaptations, initiated by exercise, can be amplified or reduced by nutrition. Various methods have been discussed to optimize training adaptations and some of these methods have been subject to extensive study. To date, most methods have focused on skeletal muscle, but it is important to note that training effects also include adaptations in other tissues (e.g., brain, vasculature), improvements in the absorptive capacity of the intestine, increases in tolerance to dehydration, and other effects that have received less attention in the literature. The purpose of this review is to define the concept of periodized nutrition (also referred to as nutritional training) and summarize the wide variety of methods available to athletes. The reader is referred to several other recent review articles that have discussed aspects of periodized nutrition in much more detail with primarily a focus on adaptations in the muscle.

The purpose of this review is not to discuss the literature in great detail but to clearly define the concept and to give a complete overview of the methods available, with an emphasis on adaptations that are not in the muscle. Whilst there is good evidence for some methods, other proposed methods are mere theories that remain to be tested. 'Periodized nutrition' refers to the strategic combined use of exercise training and nutrition, or nutrition only, with the overall aim to obtain adaptations that support exercise performance. The term nutritional training is sometimes used to describe the same methods and these terms can be used interchangeably. In this review, an overview is given of some of the most common methods of periodized nutrition including 'training low' and 'training high', and training with low- and high-carbohydrate availability, respectively. 'Training low' in particular has received considerable attention and several variations of 'train low' have been proposed. 'Training low' studies have generally shown beneficial effects in terms of signaling and transcription, but to date, few studies have been able to show any effects on performance.

In addition to 'train low' and 'train high', methods have been developed to 'train the gut', train hypo hydrated (to reduce the negative effects of dehydration), and train with various supplements that may increase the training adaptations longer term. Which of these methods should be used depends on the specific goals of the individual and there is no method (or diet) that will address all needs of an individual in all situations? Therefore, appropriate practical application lies in the optimal combination of different nutritional training methods. Some of these methods have already found their way into the training practices of athletes, even though evidence for their efficacy is sometimes scarce at best. Many pragmatic questions remain unanswered and another goal of this review is to identify some of the remaining questions that may have great practical relevance and should be the focus of future research.

\subsection{Mastery level of achievement}

Mastery learning is an instructional approach in which educational progress is based on demonstrated performance, not curricular time. Learners practice and retest repeatedly until they reach a designated mastery level; the final level of achievement is the same for all, although time to mastery may vary. Given the unique properties of mastery learning assessments, a thoughtful approach to establishing the performance levels and metrics that determine when a learner has demonstrated mastery is essential. Standard-setting procedures require modification when used for mastery learning settings in health care, particularly regarding the use of evidence-based performance data, the determination of appropriate benchmark or comparison groups, and consideration of patient safety consequences. Information about learner outcomes and past performance data of learners successful at the subsequent level of training can be more helpful than traditional information about test performance of past examinees. The marginally competent "borderline student" or "borderline group" referenced in traditional item-based and examinee-based procedures will generally need to be redefined in mastery settings. Patient safety considerations support conjunctive standards for key knowledge and skill subdomains and for items that have an impact on clinical outcomes.

Finally, traditional psychometric indices used to evaluate the quality of standards do not necessarily reflect 
critical measurement properties of mastery assessments. Mastery learning and testing are essential to the achievement and assessment of entrusting able professional activities and residency milestones. With careful attention, sound mastery standard-setting procedures can provide an essential step toward improving the effectiveness of health professions education, patient safety, and patient care.

Although several studies have investigated the roles of teaching practices during the learning process of students, the role of school learned helplessness (LH) and mastery orientation (MO) has not been deeply examined. The present study aimed to verify the dynamics between academic achievement and the perception of the students of their teacher's psychological control and autonomy support by examining the mediating role of school LH and MO. Results confirmed that perceived teacher psychological control can predict school LH, whereas perceived teacher autonomy support can predict school MO. Additionally, academic achievement was positively predicted by school MO, whereas it was negatively predicted by school LH. Finally, analyses have shown that school LH and MO play a mediating role in the relationship between academic achievement and the perceived teacher autonomy support and psychological control. Limitations and implications are discussed.

\subsection{Water, sanitation, and hygiene}

There is scarce research and programmatic evidence on the effect of poor water, sanitation, and hygiene (WASH) conditions of the physical environment on early child cognitive, sensorimotor, and socioemotional development. Furthermore, many common WASH interventions are not specifically designed to protect babies in the first 3 years of life, when gut health and linear growth are established. We review the evidence linking WASH, anemia, and child growth, and highlight pathways through which WASH may affect early child development, primarily through inflammation, stunting, and anemia. Environmental enteropathy, a prevalent subclinical condition of the gut, maybe a key mediating pathway linking poor hygiene to developmental deficits. Current early child development research and programs lack evidence-based interventions to provide a clean play and infant feeding environment in addition to established priorities of nutrition, stimulation, and child protection. Solutions to this problem will require appropriate behavior change and technologies that are adapted to the social and physical context and conducive to infant play and socialization. We propose the concept of baby WASH as an additional component of early childhood development programs.

McMichael (2019) conducted a study which states that many schools in low-income countries have inadequate access to water facilities, sanitation, and hygiene promotion. A systematic review of the literature was carried out that aimed to identify and analyze the impact of water, sanitation, and hygiene interventions (WASH) in schools in low-income countries. Published peer-reviewed literature was systematically screened during March to June 2018 using the databases PubMed, Embase, Web of Science, the Cochrane Library, Science Direct, and Google Scholar. There were no publication date restrictions. Thirty-eight peer-reviewed papers were identified that met the inclusion criteria. The papers were analyzed in groups, based on four categories of reported outcomes: (i) reduction of diarrhoeal disease and other hygiene-related diseases in school students; (ii) improved WASH knowledge, attitudes, and hygiene behaviors among students; (iii) reduced disease burden and improved hygiene behaviors in students' households and communities; (iv) improved student enrolment and attendance. The typically unmeasured and unreported 'output' and/or 'exposure' of program fidelity and adherence was also examined.

Several studies provide evidence of positive disease-related outcomes among students, yet other assessments did not find statistically significant differences in health or indicated that outcomes are dependent on the nature and context of interventions. Thirteen studies provide evidence of changes in WASH knowledge, attitudes, and behaviors, such as hand-washing with soap. Further research is required to understand whether and how school-based WASH interventions might improve hygiene habits and health among wider families and community members. Evidence of the impact of school-based WASH programs in reducing student absence from school was mixed. Ensuring access to safe and sufficient water and sanitation and hygiene promotion in schools has great potential to improve health and education and to contribute to inclusion and equity, yet 
delivering school-based WASH intervention does not guarantee good outcomes. While further rigorous research will be of value, political will and effective interventions with high program fidelity are also key.

\subsection{Intensified nutrition}

According to Patwari (2013) Reduction in prevalence of underweight children (under five years of age) has been included as an indicator for one of the targets to eradicate extreme poverty and hunger (Goal 1) of the Millennium Development Goals (MDGs). The most recent MDG report of 2012 indicates that the target of reducing extreme poverty by half has been reached five years ahead of the 2015 deadline but close to one-third of children in Southern Asia were underweight.

According to Bürger et al. (1993) Malnutrition and cachexia are characteristic symptoms of the human immunodeficiency virus (HIV)-1 infection and AIDS. To identify risk situations that might affect nutritional behavior and status and to evaluate the therapeutic effect of an intensified oral nutritional intervention, we analyzed 81 consecutively treated homosexual HIV-infected outpatients with malnutrition retrospectively and could follow the outcome of a nutritional intervention prospectively in 54 of them. Nutritional therapy was ineffective for only 5 of the 54 patients; constant weight loss could be stopped in 31 of the patients, and 18 patients could even gain weight. We suggest intensified oral nutritional intervention should be an integral part of the treatment of HIV-infected patients to prevent or treat malnutrition.

\subsection{Hygiene goals}

According to Ruel et al. (2013), acceleration of progress in nutrition will require effective, large-scale nutrition-sensitive programs that address key underlying determinants of nutrition and enhance the coverage and effectiveness of nutrition-specific interventions. We reviewed the evidence of nutritional effects of programs in four sectors-agriculture, social safety nets, early child development, and schooling. The need for investments to boost agricultural production, keep prices low, and increase incomes is undisputable; targeted agricultural programs can complement these investments by supporting livelihoods, enhancing access to diverse diets in poor populations, and fostering women's empowerment. However, evidence of the nutritional effect of agricultural programs is inconclusive-except for vitamin A from biofortification of orange sweet potatoes-largely because of poor quality evaluations. Social safety nets currently provide cash or food transfers to a billion poor people and victims of shocks. Individual studies show some effects on younger children exposed for longer durations, but weaknesses in nutrition goals and actions, and poor service quality probably explain the scarcity of overall nutritional benefits.

Combined early child development and nutrition interventions show promising additive or synergistic effects on child development - and in some cases, nutrition — and could lead to substantial gains in cost, efficiency, and effectiveness, but these programs have yet to be tested at scale. Parental schooling is strongly associated with child nutrition, and the effectiveness of emerging school nutrition education programs needs to be tested. Many of the programs reviewed were not originally designed to improve nutrition yet have great potential to do so. Ways to enhance programmed nutrition sensitivity include: improve targeting; use conditions to stimulate participation; strengthen nutrition goals and actions; and optimize women's nutrition, time, physical and mental health, and empowerment. Nutrition-sensitive programs can help scale up nutrition-specific interventions and create a stimulating environment in which young children can grow and develop to their full potential.

\subsection{Significance of the study}

This study hopes to contribute to improvement of mastery level in Health Education. It is hoped that the study findings will be useful to the policymakers, district supervisors, school administrators, teachers, and students. 
Pupils - As the direct recipients of the school, the result may give them the direction and a chance for greater involvement and wellness. Further, it can give them opportunities to get a positive impact on their academic achievement and the increasing of their competence. The self-learning tendencies toward course material taught by self-learning.

Teachers - The teachers will benefit from the findings of the study since they will become part of the study where it will increase their knowledge about the approach being used in the current curriculum they use. It may also provide them a chance to contribute for the increase in the level of performance of their students in Health Education.

School Administrators - This study may help the heads of the educational institution to identify factors that may contribute to the improvement of school and student performance in Health Education.

DepED Officials - The results of the study will provide DepED officials with sound bases in planning for the trainings needed by health education teachers with the use of the enhance learning through intensified nutrition and hygiene goals and awareness in improving academic performance.

Educational Planners - The educational planners may benefit from this study because they can use the results as a basis in determining the aspect of teaching and learning area for development.

Policy Makers - In making educational policies it is necessary that they have support to justify the existence of policies of the Department of Education. In connection with school management, they need to consider that the responsibilities associated with improved learning outcomes should be given emphasis.

Future Researchers - This study may provide other researchers with information on contributing factors to the advantages and disadvantages in the use of Enhance Learning through Intensified Nutrition and Hygiene Goals and awareness in improving Academic Performance in Health 4 that can affect the academic standing of the students.

\section{Methodology}

\subsection{Action research questions}

To investigate how pupils enhanced learning through intensified nutrition and hygiene goals in improving master level in Health 4. Specifically, answers to the following questions will be sought: How do intensified nutrition and hygiene goals awareness can help to improve the level of mastery in Health Education? This study aims to investigate how pupils enhanced learning through intensified nutrition and hygiene goals in improving mastery level in Health 4. Intensified nutrition and hygiene goals, localized/ indigenized instructional materials are important to support for the learners who are nutritionally at risk and have a low mastery level of achievement in Health. By continuously supported by the program of the Department of Education with the cooperation of the school.

\begin{tabular}{|l|c|}
\hline Independent Variables & Dependent Variables \\
\hline Intensifying nutrition and hygiene goals & $\begin{array}{c}\text { Increase pupils' mastery level of } \\
\text { achievement in Health } 4\end{array}$ \\
\hline
\end{tabular}


The present study will utilize purposive sampling in the selection of respondents coming from 146 Grade Four pupils. According to Crossman (2016), quota sampling is defined as a sampling technique that involves the identification of a set of characteristics of a population. The individuals are assumed to be alike concerning characteristics relevant to the variable considered in this research. The study will make use of the observation checklist to measure the effectiveness of intensified nutrition and hygiene goals, localized/ indigenized instructional materials to improve the mastery achievement level of the pupils

\section{Table 1}

Implementation plan

\begin{tabular}{|c|c|c|c|c|c|}
\hline \multirow[b]{2}{*}{ Activities } & \multirow[b]{2}{*}{ Target Output } & \multicolumn{2}{|c|}{ Timeline } & \multirow[b]{2}{*}{ Persons Responsible } & \multirow[b]{2}{*}{ Resources Needed } \\
\hline & & Starting Date & $\begin{array}{c}\text { Completion } \\
\text { Date }\end{array}$ & & \\
\hline $\begin{array}{l}\text { Height \& Weight } \\
\text { Determination }\end{array}$ & $\begin{array}{c}100 \% \text { of learners } \\
\text { being weighted }\end{array}$ & June 10, 2019 & June 14, 2019 & $\begin{array}{c}\text { School Principal } \\
\text { School Feeding Coordinator } \\
\text { Grade } 4 \text { nutritionally risks } \\
\text { learners }\end{array}$ & $\begin{array}{l}\text { Nutritional form or SF } \\
8 \text { Learner's Basic } \\
\text { Health and Nutrition } \\
\text { Report }\end{array}$ \\
\hline $\begin{array}{l}\text { Pre-Analysis of } \\
\text { Nutritional status and } \\
\text { Learners Profile }\end{array}$ & $\begin{array}{c}100 \% \text { of learners } \\
\text { being weighted }\end{array}$ & June 17, 2019 & June 18, 2019 & $\begin{array}{c}\text { School Principal } \\
\text { School Feeding Coordinator } \\
\text { Grade } 4 \text { nutritionally risks } \\
\text { learners }\end{array}$ & $\begin{array}{c}\text { Nutritional form or SF } \\
8 \text { Learner's Basic } \\
\text { Health and Nutrition } \\
\text { Report }\end{array}$ \\
\hline $\begin{array}{l}\text { Orientation/ Briefing } \\
\text { and Signing of Pledge } \\
\text { of Commitment with } \\
\text { the Health Teacher } \\
\text { and pupils on the } \\
\text { implementation of the } \\
\text { project }\end{array}$ & $\begin{array}{c}\text { Continuous } \\
\text { implementation of } \\
\text { programs and projects }\end{array}$ & July 1, 2019 & $\begin{array}{l}\text { August 1, } \\
2019\end{array}$ & $\begin{array}{c}\text { School Principal } \\
\text { School Feeding Coordinator } \\
\text { MAPEH teacher } \\
\text { Grade } 4 \text { nutritionally risks } \\
\text { learners }\end{array}$ & $\begin{array}{c}\text { Copy of } \\
\text { implementation plan } \\
\text { and pilot solutions }\end{array}$ \\
\hline $\begin{array}{c}\text { Make / Developed } \\
\text { localized IM's suitable } \\
\text { to Health and Hygiene } \\
\text { Lessons }\end{array}$ & $\begin{array}{c}\text { Development of } \\
\text { Teacher's made IM's } \\
\text { to support Health and } \\
\text { Hygiene Lesson }\end{array}$ & $\begin{array}{l}\text { August 2, } \\
2019\end{array}$ & $\begin{array}{c}\text { December 13, } \\
2019\end{array}$ & Grade 4 MAPEH teacher & $\begin{array}{l}\text { Bond paper } \\
\text { Ink } \\
\text { Test materials }\end{array}$ \\
\hline $\begin{array}{c}\text { Quarterly } \\
\text { consolidation/evaluati } \\
\text { on of test results using } \\
\text { varied teaching } \\
\text { strategies/IM's }\end{array}$ & $\begin{array}{l}100 \% \text { cooperation in } \\
\text { the implementation of } \\
\text { the programs and } \\
\text { projects }\end{array}$ & June 17, 2019 & $\begin{array}{c}\text { December 13, } \\
2019\end{array}$ & Grade 4 MAPEH teacher & $\begin{array}{l}\text { Copy of } \\
\text { implementation plan } \\
\text { and pilot solutions }\end{array}$ \\
\hline $\begin{array}{c}\text { Collection/Tabulation } \\
\text { of Data }\end{array}$ & $\begin{array}{l}6 \text { out of } 8 \text { nutritionally } \\
\text { risks pupils have } \\
\text { reached the } 75 \% \text { level } \\
\text { of proficiency }\end{array}$ & $\begin{array}{c}\text { January } 20, \\
2020\end{array}$ & $\begin{array}{c}\text { January } 31, \\
2020\end{array}$ & Grade 4 MAPEH teacher & Tabulation form \\
\hline $\begin{array}{c}\text { Analysis and } \\
\text { Comparison of pupil's } \\
\text { test results }\end{array}$ & $\begin{array}{l}6 \text { out of } 8 \text { nutritionally } \\
\text { risks pupils have } \\
\text { reached the } 75 \% \text { level } \\
\text { of proficiency }\end{array}$ & $\begin{array}{l}\text { February } 13, \\
2020\end{array}$ & & Grade 4 MAPEH teacher & Test Results \\
\hline $\begin{array}{c}\text { Culminating } \\
\text { Activities/Celebration } \\
\text { of Success }\end{array}$ & $\begin{array}{l}6 \text { out of } 8 \text { nutritionally } \\
\text { risks pupils meet the } \\
\text { target increase level of } \\
\text { proficiency }\end{array}$ & $\begin{array}{l}\text { March 12, } \\
2020\end{array}$ & $\begin{array}{l}\text { March 12, } \\
2020\end{array}$ & $\begin{array}{c}\text { School Principal } \\
\text { School Feeding Coordinator } \\
\text { Section Advisers } \\
\text { MAPEH teacher } \\
\text { Grade } 4 \text { nutritionally risks } \\
\text { learners } \\
\end{array}$ & Awards/Incentives \\
\hline
\end{tabular}

\section{Findings and discussion}

This study revealed the following finding:

The mastery level of the Grade 4 pupils in Health 4 increased through intensified nutrition and hygiene goals awareness. According to the study of Silvestre, M. D. P. explored the lived experiences of teachers teaching music, arts, physical education, and health in the island of Mindanao, province of Bukidnon, Philippines. The study focuses on how the PEHM teachers teach Music, Art, PE, Health as to content knowledge, strategy, use of instructional materials, and assessment. Qualitative research using a phenomenological approach was used in the study. The participants were chosen purposely. The study made use of Collaizzi's(1978) model. Lack of competencies in the specializations of teachers teaching MAPEH was evident. Graduate education has to offer programs that would address the necessary competencies of teachers. The 21st Century Skills are wanting in the field of teaching MAPEH. Teachers' knowledge, skills, and competencies in MAPEH could not be 
strengthened effectively and efficiently through seminars and workshops only. HEIs could offer courses that would address the needs of the MAPEH teachers contextualizing the lessons and emphasizing the 21st Century Skills particularly the critical thinking skills integrating technology. With the Special Program in the Arts tract in the $\mathrm{K}$ to 12 Curriculum and the program offering of CHED in the Bachelor of Culture and Arts Education, the Graduate Education could help equip these teachers by offering advanced degree programs align with the need of teachers especially in terms of teaching strategies, instructional materials, mastery of content knowledge and assessment in various specializations in MAPEH. The table shows the comparison of learners' mastery level of achievement in Health 4 from the First Quarter to Fourth Quarter.

Table 2

Mastery level of achievement

\begin{tabular}{|c|c|c|c|c|c|c|c|}
\hline \multirow[b]{2}{*}{$\begin{array}{l}\text { Grading } \\
\text { Period }\end{array}$} & \multicolumn{7}{|c|}{ Mastery Level Of Achievement } \\
\hline & $\begin{array}{c}\text { Mastered (M) } \\
96-100 \%\end{array}$ & $\begin{array}{c}\text { Closely } \\
\text { Approximating } \\
\text { Mastery (Cam) } \\
86-95 \%\end{array}$ & $\begin{array}{c}\text { Moving } \\
\text { Towards } \\
\text { Mastery }(\mathrm{Mtm}) \\
66-85 \%\end{array}$ & $\begin{array}{c}\text { Average } \\
\text { (Avr) } 35-65 \%\end{array}$ & $\begin{array}{l}\text { Low (L) } \\
15-34 \%\end{array}$ & $\begin{array}{c}\text { Very } \\
\text { Low (V1) } \\
5-14 \%\end{array}$ & $\begin{array}{l}\text { No Mastery } \\
\text { (Anm) } 0-4 \%\end{array}$ \\
\hline First & 1 & 0 & 2 & 5 & 0 & 0 & 0 \\
\hline Second & 0 & 2 & 3 & 3 & 0 & 0 & 0 \\
\hline Third & 1 & 1 & 2 & 4 & 0 & 0 & 0 \\
\hline
\end{tabular}

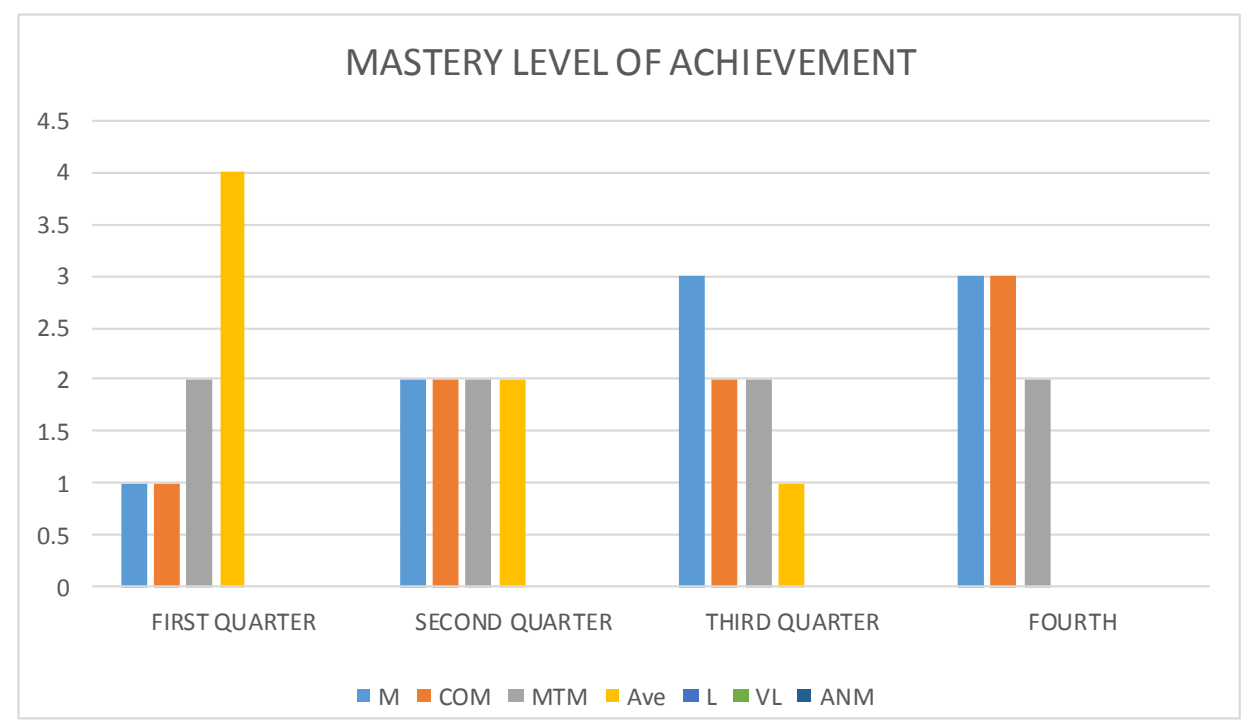

The graph shows that their mastery level in Health 4 from the First Quarter increased until Fourth Quarter using intensified nutrition and hygiene goals, localized/ indigenized instructional materials. Intensified nutrition and hygiene goals, localized/ indigenized instructional materials are important to support for the learners who are nutritionally at risk and have a low mastery level of achievement in Health. By continuously supported by the program of the Department of Education with the cooperation of the school.

\section{Conclusion}

After determining the Focused Problem Statement that 8 out of 147 Grade 4 learners are nutritionally at risk and have low mastery achievement level in Health. Voice of the customer was conducted to discover the root cause analysis and possible solutions to the problem. Eating unhealthy foods, no proper personal hygiene, no follow-up study at home, Inattentiveness during the intervention period, Pupils tend to forget the lesson easily, can't understand HOTS questions were the root cause analysis. Supply nutritious foods, Orientation on proper hygiene, Developed Teacher made IM's to support Health \& Hygiene lessons were the possible solutions respectively. 
Project E-LINGAP plays a vital role in supporting and achieving the effectiveness of intensified nutrition and hygiene goals, localized/ indigenized instructional materials to improve the mastery achievement level of the pupils. Intensified nutrition and hygiene goals, localized/ indigenized instructional materials are important to support for the learners who are nutritionally at risk and have a low mastery level of achievement in Health. By continuously supported by the program of the Department of Education with the cooperation of the school.

Acknowledgments - A considerable number of people are not worthy of respect and admiration because no undertaking of this kind is accomplished without the moral, technical, intellectual, and financial support of the following individuals who helped us to complete our research study. We would like to wholeheartedly thank Dr. EVELYN S. JOCSON, Ed.D, District Supervisor of Magdalena-Majayjay for allowing us to conduct our action research. To our very supportive Principal, Mrs. SEVERA C. VERSOLA for imparting her expertise in the field of research. To all the Grade Four Teachers and Pupils for their cooperation, untiring support, and understanding is given to us in conducting this research. To our Family and Friends that gave us the courage and who are with us during the struggle of doing this research. All the glory and honor are for the Lord God who deserves most of gratitude.

\section{References}

Abdulrahman, A. K. B., et al. (2019). Do various personal hygiene habits protect us against influenza-like illness? BMC Public Health, 19(1), 1-8. https://doi.org/10.1186/s12889-019-7726-9

Bryce, J., et al. (2008). Maternal and child undernutrition: effective action at the national level. The Lancet, 371(9611), 510-526. https://doi.org/10.1016/S0140-6736(07)61694-8

Bürger, B., et al. (1993). Nutrition behavior of malnourished HIV-infected patients and intensified oral nutritional intervention. Nutrition, 9(1), 43-44.

del Castillo, F. A., et al. (2020). Lessons from COVID19: Advocacy toward the vulnerable. Journal of Public Health, 42(4), 869-870. https://doi.org/10.1093/pubmed/fdaa121

Dingwall, L. (2010). Personal Hygiene Care. In Personal Hygiene Care. https://doi.org/10.1002/9781444318708

Filippello, P., Buzzai, C., Costa, S., Orecchio, S., \& Sorrenti, L. (2020). The teaching style and academic achievement: The mediating role of learned helplessness and mastery orientation. Psychology in the Schools, 57(1), 5-16. https://doi.org/10.1002/pits.22315

Jeukendrup, A. E. (2017). Periodized nutrition for athletes. Sports medicine, 47(1), 51-63. https://doi.org/10.1007/s40279-017-0694-2

Leibler, J. H., et al. (2017). Personal hygiene practices among urban homeless persons in Boston, MA. International Journal of Environmental Research and Public Health, 14(8), 928. https://doi.org/10.3390/ijerph14080928

McMichael, C. (2019). Water, sanitation, and hygiene (WASH) in schools in low-income countries: A review of the evidence of impact. International Journal of Environmental Research and Public Health, 16(3), 359. https://doi.org/10.3390/ijerph16030359

Ngure, F. M., et.al (2014). Water, sanitation, and hygiene (WASH), environmental enteropathy, nutrition, and early child development: Making the links. Annals of the New York Academy of Sciences. https://doi.org/10.1111/nyas. 12330

Patwari, A. K. (2013). Millennium development goals and child undernutrition. Indian pediatrics, 50(5), 449-452. https://doi.org/10.1007/s13312-013-0144-7

Ringler, C., et al. (2018). Meeting the nutrition and water targets of the sustainable development goals: achieving progress through linked interventions (Vol. 7). Colombo, Sri Lanka: International Water Management Institute (IWMI). CGIAR Research Program on Water, Land, and Ecosystems (WLE). https://doi.org/10.5337/2018.221

Ruel, M. T., et.al (2013). Nutrition-sensitive interventions and programs: how can they help to accelerate progress in improving maternal and child nutrition? The Lancet, 382(9891), 536-551.

32 Consortia Academia Publishing (A partner of Network of Professional Researchers and Educators) 
https://doi.org/10.1016/S0140-6736(13)60843-0

Silvestre, M. D. P., \& Itaas, E. C. (2020). Lived experiences of teachers teaching music, arts, physical education, and health: Implications to Graduate Education. International Journal of Innovative Science and Research Technology, 5(12), 1262-1268.

World Health Organization. (2004). Personal, domestic, and community hygiene. Healthy Villagers: A Guide for Communities and Community Health Workers (pp. 65-73). https://www.who.int/water_sanitation_health/hygiene/settings/hvchap8.pdf

Yudkowsky, R., Park, Y. S., Lineberry, M., Knox, A., \& Ritter, E. M. (2015). Setting mastery learning standards. Academic Medicine, 90(11), 1495-1500. https://doi.org/10.1097/ACM.0000000000000887

Zamora, O. B., de Guzman, L. E. P., Saguiguit, S. L. C., Talavera, M. T. M., \& Gordoncillo, N. P. (2013). Leveraging agriculture to improve nutrition in the Philippines. Food Security, 5(6), 873-886. https://doi.org/10.1007/s12571-013-0306-4 
Capuz, J.

34 Consortia Academia Publishing (A partner of Network of Professional Researchers and Educators) 